\title{
Biochar application and no-tillage practices to minimize the residues of herbicides in the seeding hole
}

\author{
Ashutus Singha ${ }^{1 *} \mathbb{D}$, Md. Arifur Rahaman', Md. Abu Sayem Jiku', Muhiuddin Faruquee², Md. Ashraful Alam ${ }^{3}$ and \\ Shata Rupa Sinha ${ }^{4}$
}

\begin{abstract}
Background: No-tillage is considered as a promising alternative for conventional farming by saving energy input and time, reducing groundwater pollution, and counteracting soil erosion and losses of soil-organic matter. Therefore, this study was carried out in north-eastern Sylhet of Bangladesh during the period of 2015-2016 to evaluate the multiple techniques of implementation in order to find a practically appropriate way to apply biochar.

Results: In this study, successfully applied of biochar and glyphosate in holes with seeds and consisted of one control (pure soil), glyphosate control, biochar control, and four glyphosate treatments with 1, 2.5, 5, and 10\% biochar addition. The Gly + ch1\% and Gly + ch2.5\% treatments demonstrated a better emergence rate than all treatments, and at the end of the emergence, they reached more than 95\%. There was no important distinction found among all the treatments in the event of shooting fresh and dry biomass. Biochar amendment treatments did not show any influence on shoot fresh biomass compared to glyphosate control and biochar 5\% treatment, respectively. Gly + ch2.5\% treatment showed slightly better performance than all the other treatments. The similar performance was shown in case of shoot dry weight. In case of root fresh weight, there was only a significant different observed between Gly + ch1\% and Gly + ch10\%. However, Gly + ch1\% treatment revealed slightly higher root fresh weight compared to all the other treatments. Considering the results of the germination percentage and root morphology, it could be suggested that lower rate of biochar application showed better performance on root length and development.
\end{abstract}

Conclusions: It could be concluded that glyphosate application has mitigation effect to absorb herbicidal residues. For successful introduction of biochar application in agriculture, field acts as a huge amount of carbon sink and has also a positive effect to mitigate climate change.

Keywords: Seedling emergence, No-tillage practice, Biochar, Glyphosate, Seeding hole

\section{Introduction}

No-tillage is considered as a promising alternative for conventional farming by saving energy input and time, reducing groundwater pollution, and counteracting soil erosion and losses of soil-organic matter. However, farmers of no-tillage area especially on Southwest Germany are increasingly facing problems particularly in winter wheat and oilseed rape production (Schmitz et al.

\footnotetext{
* Correspondence: ashutus.iwm@sau.ac.bd

${ }^{1}$ Institute of Environmental and Sustainable development in Agriculture

Chinese Academy of Agricultural Science, Beijing 10081, China

Full list of author information is available at the end of the article
}

2012). However, glyphosate application in mulch seeding plot and in direct seeding systems is also growing popularity in Germany (Müller 2011). On the contrary, climate change is a big threat for unploughed soil atmosphere in the North-Eastern part of Bangladesh which effects in dropping crop production and has its ultimate effect on food security (Khan et al. 2014). Depending on environmental conditions, the non-tillage can provide few benefits compared to conventional tillage system, such as better conservation of water in the soil (Alvarez and Steinbach 2009; Jin et al. 2011; Putte et al. 2010); increase the organic carbon contents and the microbial 
biomass in topsoil (Babujia et al. 2010; Bhattacharyya et al. 2009); decrease the maximum daily soil temperature in tropical regions (Derpsch et al. 1986); and increase soil biodiversity (Adl et al. 2005). The increase in soil bulk density and penetration resistance in the topsoil under the non-tillage system has not reduced growth of roots and yield of most crops even after periods of over a decade (Cavalieri et al. 2009; Lima et al. 2010).

Glyphosate is the widely used non selective, systemic herbicide on global scale. After foliar spray, it is absorbed by leaves and translocated throughout leaves, stems, and roots of the whole plant, particularly accumulating in the young growing tissues (Franz et al. 1997). The herbicidal effect is based on inhibition of sikimate pathway enzyme 5-enolpyruvylshikimic acid-3phosphate synthase (EPSPS) for the biosynthesis of aromatic amino acids and phenolic compounds (DellaCioppa et al. 1986; Franz et al. 1997). However, the risk of toxicity of glyphosate to non-target organisms is generally considered as marginal because of inactivation by adsorption to clay minerals (Dong-Mei et al. 2004) and also rapid microbial decomposition (Giesy et al. 2000).

The widely used recent studies suggest a relationship between long-term glyphosate application and adverse effects on various non-target organisms in agro-ecosystems. According to Huber and McCay-Buir (1993) and King et al. (2001), the adverse effects are increased sensitivity to diseases, associated with a low $\mathrm{Mn}^{-}$and $\mathrm{Fe}^{-}$nutritional status, increased nematode infections, and inhibition of root growth, which might be induced by glyphosate interactions with the calcium metabolism, reduced honey production due to limited synthesis of flavonoids, and reduced biological nitrogen fixation. Potential risks of glyphosate toxicity to non-target plants in soils are generally considered as marginal, as glyphosate in the soil solution is prone to rapid microbial degradation (Giesy et al. 2000) or instantaneous inactivation by sorption to the soil mineral matrix (Giesy et al. 2000; Piccolo et al. 1992). However, an increasing number of studies suggested negative side effects on non-target plants supposed to be related with the intensive use of glyphosate herbicides in mulch tillage or direct seeding system.

Biochar is a carbon-rich co-product producing from pyrolyzing of biomass under high-temperature, low oxygen conditions (Laird et al. 2009; Lehmann, 2007). It contains highly condensed aromatic structures which resist decomposition in soil and thus can effectively sequester a portion of the applied carbon for decades to centuries (Lehmann 2006), although see Wardle et al. (2008). Woolf et al. (2010) reported that widespread use of biochar could mitigate up to $12 \%$ of current anthropogenic $\mathrm{CO}_{2}$ emissions.

Application of biochar through managing soil biota is a topic of growing interest and inadvertent changes of soil biota. Biochar amendment changes soil biological community and abundance (Grossman et al. 2010; Jin H et al. 2011; Liang et al. 2006). No systematic description has not been clear yet about the connection between biochar properties and the soil biota and possible impact for soil processes. Biochar could improve soil health; however, it might create a risk to soil fauna and flora. Biochar changes in microbial community composition have effect on nutrient cycles, plant growth, and the cycling of soil-organic matter (Kuzyakov et al. 2009; Liang et al. 2006).

Addition of biochar may affect the soil biological community composition on the biochar wealthy Terra preta soils within the Amazon (Grossman et al. 2010; et al. 2009) and has been also shown to increase soil microbial community (Jin et al. 2011; O'Neill et al. 2009). The abundance of microbial biomass will increase or not, as mentioned for mycorrhizal fungi (Warnock et al. 2007), and is probably connected to the intrinsic properties of biochar and also the soil.

Bio-charcoal has been used in industrial water purification for removal of various chemicals including herbicide (Simpson 2008). Glyphosate is a major water polluting herbicide, and active charcoal is being effectively used to remove it. In long-term affected soils, high residues of glyphosate confirmed delayed degradation, and these residues are harmful for the crop. As per recommendation, glyphosate is applied pre sowing and it must be degraded or bind before seeding. As bio-charcoal is being used to remove herbicide, it can be used to remove or bind herbicide residues in soil at time of seeding. But it's appropriate application method as well as proper dose in soil is still unclear. So, with this backdrop, the present study was under taken with the following specific objectives. To reach the aims the following three hypothesis of the study are considered biochar amendments can mitigate plant damage induced by glyphosate residues.

\section{Materials and methods}

\section{Experimental approach and designs}

This experiment was carried out (2015-2016) at the controlled climate chamber with 16/8-h day/night regime, temperature range of 22 to $25^{\circ} \mathrm{C}$ and humidity range of 53 to $55 \%$, at the Department of Water Resource and Environment at Sylhet Agricultural University, Bangladesh. Winter wheat (Triticum aestivum cv. Isengrain) was used as a model plant. The experiment was laid out in a completely randomized design (CRD) with seven treatments and four replications. In this experiment, roundup (glyphosate) and biochar were applied close to the seed, each pot was filled 
with $350 \mathrm{~g}$ of soil, and 10 seeding holes were made, and then, $50 \mathrm{~g}$ soil was added in seeding holes according to treatments. In control, seeding holes were filled with pure soil, and in roundup treatment, seeding holes were filled with $50 \mathrm{~g}$ soil mixed with Roundup herbicide Ultramax. In biochar treatment, $5 \% \mathrm{v} / \mathrm{v}$ biochar was mixed in $50 \mathrm{~g}$ soil and filled in seeding holes. For roundup and biochar combined treatments, roundup herbicide Ultramax ${ }^{\circ}$ was mixed with biochar $1 \%, 2.5 \%$, $5 \%$, and $10 \% \mathrm{v} / \mathrm{v}$, mixed with $50 \mathrm{~g}$ soil for each treatment separately, and filled in seeding holes. After a 24-h waiting time, 10 seeds were sown in each pot's seeding hole and each pot was topped with layer of find sand to reduce evaporation. Every day, the pots were randomized and watered. The data were recorded, and photos were taken every $48 \mathrm{~h}$ for 2 weeks. The treatments were pure soil (control), soil mixed with roundup herbicide (glyphosate) Ultramax ${ }^{\circ} 6 \mathrm{~L} / \mathrm{ha}$ (Gly), soil mixed with $5 \% \mathrm{v} / \mathrm{v}$ biochar (Gly), roundup herbicide (glyphosate) Ultramax ${ }^{\circ}$ at $6 \mathrm{~L} /$ ha dose with $1 \% \mathrm{v} / \mathrm{v}$ biochar (Gly + Bio-Char $1 \%)$, roundup herbicide (glyphosate) Ultramax at $6 \mathrm{~L} /$ ha dose with $2.5 \% \mathrm{v} / \mathrm{v}$ biochar (Gly + Bio-Char 2.5\%), roundup herbicide (glyphosate) Ultramax at $6 \mathrm{~L} /$ ha dose with $5 \%$ $\mathrm{v} / \mathrm{v}$ biochar (Gly + Bio-Char 5\%), and roundup herbicide (glyphosate) Ultramax at $6 \mathrm{~L} / \mathrm{ha}$ dose with $10 \% \mathrm{v} / \mathrm{v}$ biochar (Gly + Bio-Char 10\%).

\section{Data collection}

\section{Germination \% calculation}

The number of seed germination, out of 10 seeds sown, was recorded for each treatment, after 24-h interval and percentage were calculated using the following formula

Germination Calculation $(\%)=($ Number of seeds germinated $)$ /Number of seeds sown) $x 100$

\section{SPAD value measurement}

SPAD value of wheat leaves was collected from each plant and measured to determine nutrient status of the plants. The chlorophyll meter (SPAD-502, Minolta Camera Co., Osaka, Japan, Minolta Co., 2013) was used to measure the SPAD value. The SPAD value was taken from each youngest fully developed leaf to finally get an average value of chlorophyll content.

\section{Fresh and dry biomass of shoot and root}

After harvesting, shoots were cut above the top soil level and weighed for the fresh biomass. The fresh shoots were dried in oven at $40^{\circ} \mathrm{C}$ for 3 days, and dry matter was determined by weighing. In case of root biomass, the same method took place after carefully washing soil and removal of all organic and biochar particles.

\section{Root morphology}

Roots in $20 \%$ ethanol solution were maintained before dry oven. The root system was distributed on the scanner plate and scanned with a scanner (Epson Perfection V700 Photo, Epson, USA) for the image of each treatment. The image was analyzed with WinRHIZO software (Regent Instruments Inc., Canada) to observe the root morphology. Root length was measured considering the diameter classes $(0.0-0.2 \mathrm{~mm}, 0.2-0.4 \mathrm{~mm}, 0.4-0.6$ $\mathrm{mm}, 0.6-0.8 \mathrm{~mm}, 0.8-1 \mathrm{~mm}, 1-1.2 \mathrm{~mm}$, and $>1.2 \mathrm{~mm}$ ) of the total root system. Total root length and total root average diameter were also measured.

\section{Statistics}

Pots were arranged in the climate chamber in a completely randomized design, and all treatments comprised four replicates. Statistical analysis of variance was performed by using Sigma plot 12 statistics software package by comparing means through one-way-ANOVA (Sigma plot, Systat. Software Inc., USA).

\section{Results \\ Emergence of seedlings}

The emergence of seedlings occurred 4 days after seeding. Gly $+\mathrm{ch} 1 \%$, Gly $+\mathrm{ch} 2.5 \%$, and ch $5 \%$ treatments have shown significant difference compared to Gly $+\mathrm{ch} 5 \%$, Gly $+\mathrm{ch} 10 \%$, and control treatment only at the fourth day after emergence, but no significant difference was revealed in emergence percentage of seeds per unit of time among the remaining treatments. Gly + ch1\% and Gly $+\mathrm{ch} 2.5 \%$ treatments showed the better germination rate than all treatments and reached above $95 \%$ at the end of emergence. At first, the control treatment showed the lowest percentage of emergence, but after the seventh day control (only soil), treatment showed similar result of emergence percentage as Gly + ch1\% and Gly + ch2.5\%. In case of glyphosate control treatments, slower emergence was observed in the beginning of emergence. However, after 7 days emergence percentage reached above $80 \%$ by showing a constant pattern at the end of emergence. At the beginning, biochar 5\%, treatment showed lower emergence whereas the similar trend was observed after the eighth day as glyphosate control treatment in the end of emergence. (Fig. 1).

The experiment consisted in addition to one control (pure soil), glyphosate control, biochar control, and 4 glyphosate treatments with $1,2.5,5$, and $10 \%$ biochar amendment. The emergence of seedlings occurred 4 days after seeding. Gly + ch1\%, Gly + ch $2.5 \%$, and ch5\% treatments have shown significant difference compared to Gly + ch $5 \%$, Gly + ch $10 \%$, and control treatment only at the fourth day after emergence, but no significant difference was revealed in emergence percentage of seeds per unit of time among the remaining treatments. Gly + 


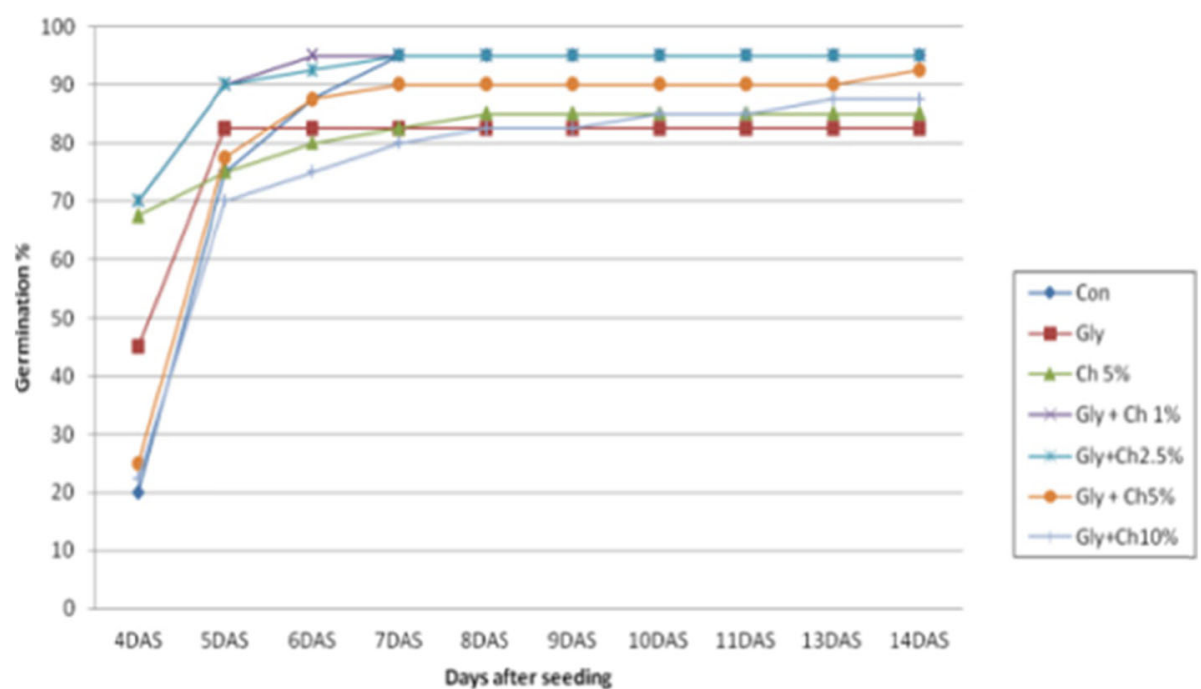

Fig. 1 Percentage of germinated winter wheat seeds among different biochar amendment treatment per day after seeding. Every data point show average treatment values of four independent replicates

ch1\% and Gly + ch2.5\% treatments showed better emergence rate than all treatments and reached above 95\% in the end of emergence.

\section{Leaf chlorophyll content}

SPAD value was measured after 12 days of emergence to determine the leaf chlorophyll content. Control treatment showed only significant difference among all treatments. Among all the biochar amendment treatments, Gly + ch10\% performed better than all other biochar amendment treatments (Fig. 2).

\section{Fresh and dry biomass of shoot}

In case of shoot fresh and dry biomass, there was no significant difference revealed among all the treatments. An increasing biochar amendment with glyphosate application did not show an effect on shoot fresh biomass compared to only glyphosate and biochar 5\% treatment respectively. Gly + ch $2.5 \%$ treatment showed slightly better performance than all the other treatments. The similar performance was shown in case of shoot dry weight. Within all the treatments, only glyphosate with $2.5 \%$ biochar amendment performed slightly higher in root dry biomass production. There was no significant

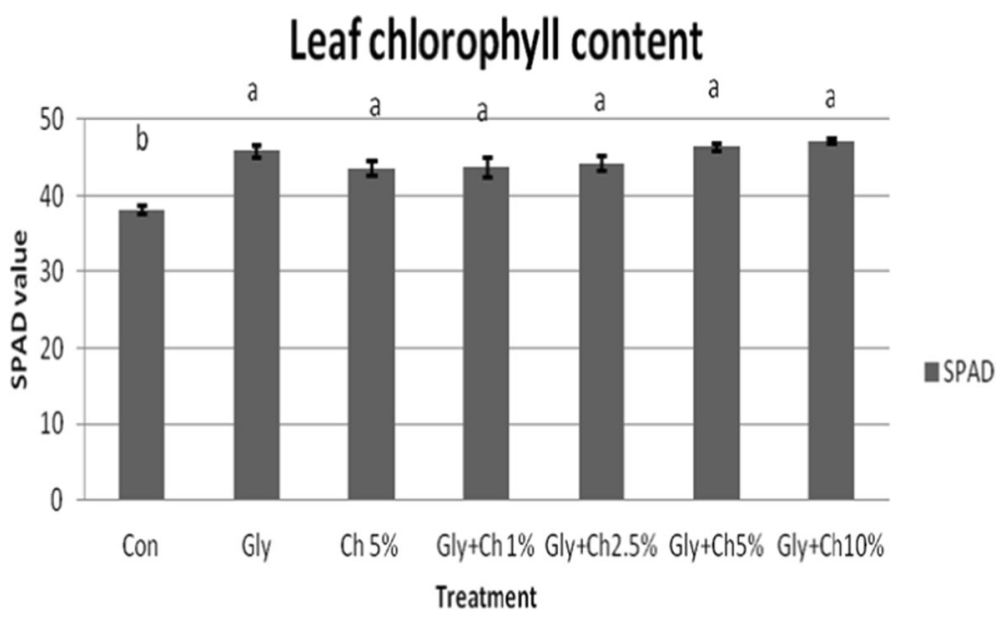

Fig. 2 Soil plant analysis (SPAD) values showing leaf chlorophyll content of winter wheat seeds (cv. Isengrain) after 12th of seeding. Every data point show average treatment values of four independent replicates. Error bars indicating standard error. Different letters indicating significant differences $(a=0.05)$ 
difference observed in case of shoot dry weight among different treatments (Fig. 3).

\section{Fresh and dry biomass of root}

In comparison to root fresh and dry weight, root fresh weight showed significant difference. There was only a significant different observed between Gly + ch $1 \%$ and Gly + ch $10 \%$. However, Gly + ch $1 \%$ treatment revealed slightly higher root fresh weight compared to all the other treatments (Fig. 4a).

In case of root dry weight measurement, there was a very small difference among all biochar amendment and glyphosate control treatment. However, comparing with Gly $+\mathrm{ch} 10 \%$, root dry weight was significantly increased in the biochar $5 \%$ treatment. The highest value of root dry weight was found in case of ch5\% treatment and the lowest value was found in case of Gly + ch10\% treatment (Fig. 4b).

In case of shoot fresh and dry biomass, there was no significant difference revealed among all the treatments. Biochar amendment treatments did not show any influence on shoot fresh biomass compared to glyphosate control and biochar $5 \%$ treatment, respectively. Gly $+\mathrm{ch} 2.5 \%$ treatment showed slightly better performance than all the other treatments. The similar performance was shown in case of shoot dry weight. Within all the treatments, glyphosate with $2.5 \%$ biochar amendment performed slightly higher in shoot dry biomass production. In case of root fresh weight, there was only a significant different observed between Gly + ch1\% and Gly + ch10\%. However, Gly + ch1\% treatment revealed slightly higher root fresh weight compared to all the other treatments. In case of root dry weight measurement, there was a very small difference observed among all biochar amendment and glyphosate control treatments.

\section{Root morphology}

In this study, root morphological analysis showed significant differences in length of the fine root diameter classes. All the treatments did not show significant difference in the root diameter range 0.0 to $0.2 \mathrm{~mm}$. Gly + ch1\% was performed significantly higher in fine root length compared to ch $5 \%$ and Gly + ch $2.5 \%$ in the diameter rang 0.2 to $0.4 \mathrm{~mm}$ (Fig. 5). In addition, Gly $+\mathrm{ch} 1 \%$ performed a similar result within root diameter range 0.4 to $0.6 \mathrm{~mm}$ and had significantly higher root length until $1.2 \mathrm{~mm}$ diameter (Fig. 6). So, there was a trend for increased fine root production by application of biochar close to the seeds in low concentrations $(1 \%, 2.5 \%)$.

In addition, among all biochar treatments, Gly + ch1\% revealed significantly better performance in root length compared to Gly + ch $5 \%$, Gly + ch $10 \%$, and $\operatorname{ch} 5 \%$, respectively. That is indicating that lower concentration of biochar amendment is better for fine root length development (Fig. 7).

Average diameter did not show any significant difference among all the treatments, whereas the higher average diameter value was observed in Gly +ch2.5\% treatment and the lower was observed in case of Gly + ch1\% and Gly + ch5\% treatments (Fig. 8).

\section{Discussion}

Biochar has an efficient sorbent of various contaminants, organic, and inorganic compounds. The sorption capacity depends on biochar carbon fraction composition that is determined by the relative carbonized and noncarbonized fractions, their surface, and bulk properties (Woolf et al. 2010). Biochar is being used to remove herbicide residues from soil at the time of seeding. Since biochar is so beneficial to adsorb organic contaminants, it is important to examine the mechanism of biochar sorption. According to many published research reports, the mechanism of organic pollutants sorption can be
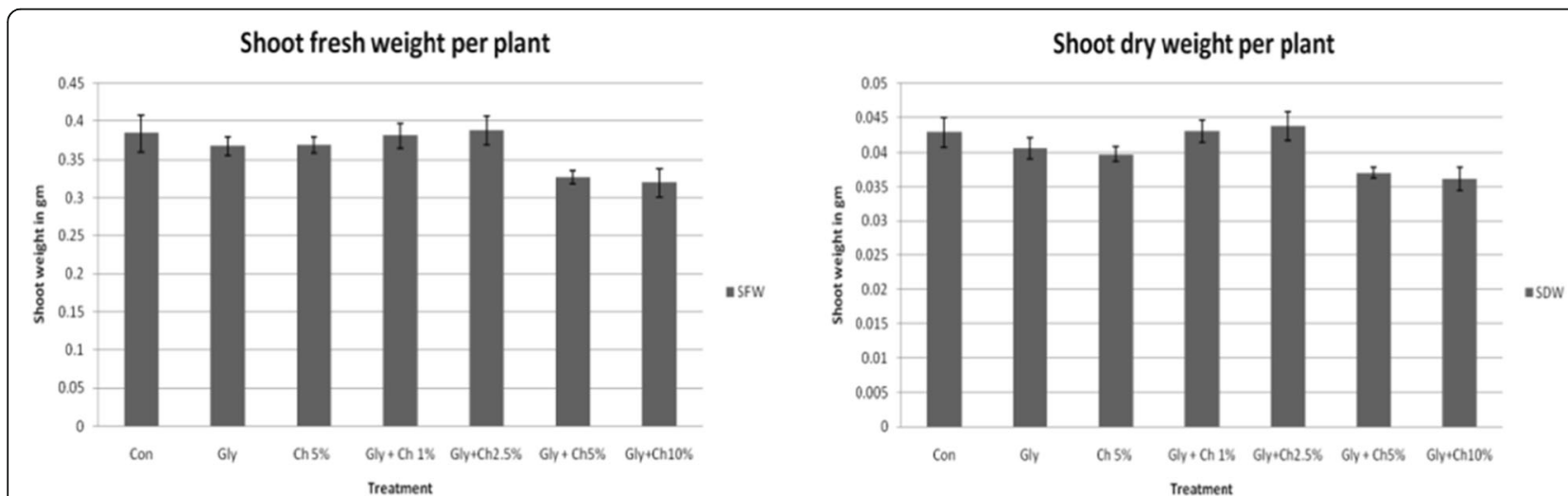

Fig. 3 Shoot fresh and dry weight values of winter wheat seedlings (cv. Isengrain) of different treatments 14 days after seeding. Every data point show average treatment values of four independent replicates. Error bars indicating standard error 

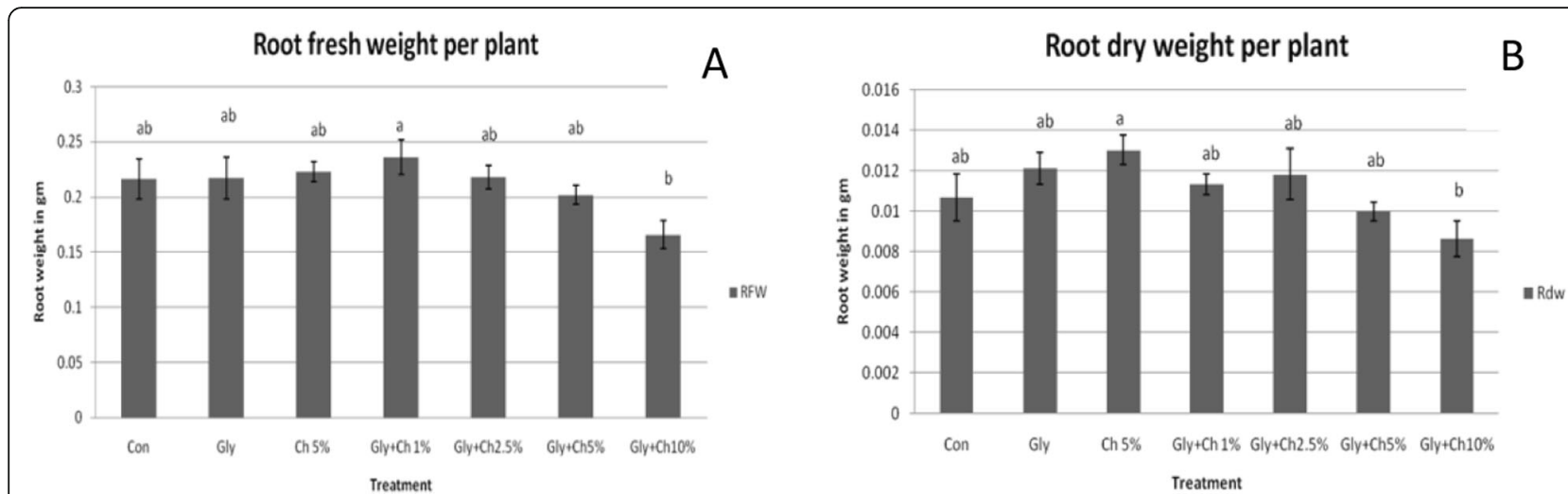

Fig. 4 (a) Root fresh and (b) dry weight values of winter wheat seedlings (cv. Isengrain) of different treatments 14 days after seeding. Every data point show average treatment values of four independent replicates. Error bars indicating standard error. Different letters above the bars indicating significant differences $(a=0.05)$. Cont $=$ pure soil without glyphosate, $\mathrm{Gly}=$ glyphosate $6 \mathrm{~L}$ dose without biochar amendment, $\mathrm{ch} 5 \%=$ biochar amendment of 5\%, Gly6L+ch1\% = glyphosate with biochar amendment of 1\%, Gly6L+ch2.5\% = glyphosate with biochar amendment of $2.5 \%$, Gly $6 \mathrm{~L}+\mathrm{ch} 5 \%$ = glyphosate with biochar amendment of 5\%, gly $6 \mathrm{~L}+\mathrm{ch} 10 \%=$ glyphosate with biochar amendment of $10 \%$

summarized as surface adsorption and partition. Sun et al. (2012) reported that two herbicide fluridone and norflurazon can be efficiently sorbed by biochar. Chen and Yuan (2011) found that application of biochar into soil may enhance the sorption of PAHs, which provide a possible reference to apply biochar to mitigating the PAHs-contaminated soils through transferring PAHs from soil to biochar. Glyphosate is a major water polluting herbicide, and active charcoal is being effectively used to remove it. In long-term affected soils, high residues of glyphosate confirmed delayed degradation and these residues are harmful for the crop (Neumann et al. 2012).

In this study, emergence of seedlings was lowest in the glyphosate treatment and highest in the variant with additional application of $5 \%$ biochar as well as in the untreated control. There was a trend for increased emergence of seedlings by application of biochar close to the seeds in low concentrations $(1 \%, 2.5 \%)$. This possible explanation could be biochar generally increased wheat seed germination at the lower concentration of biochar application and decreased or had no effect at higher rates of application (Solaiman et al. 2012).

Biochar amendment did not show positive influence on leaf chlorophyll contents compared to glyphosate control treatment. Root morphological analysis showed significant differences in length of the fine root diameter classes. Biochar treatments performed better result in root length in comparison to control without biochar treatment in the diameter range 0.0 to above $0.8 \mathrm{~mm}$, and this result is suggesting that lower concentration of biochar application could have an enhancing effect on

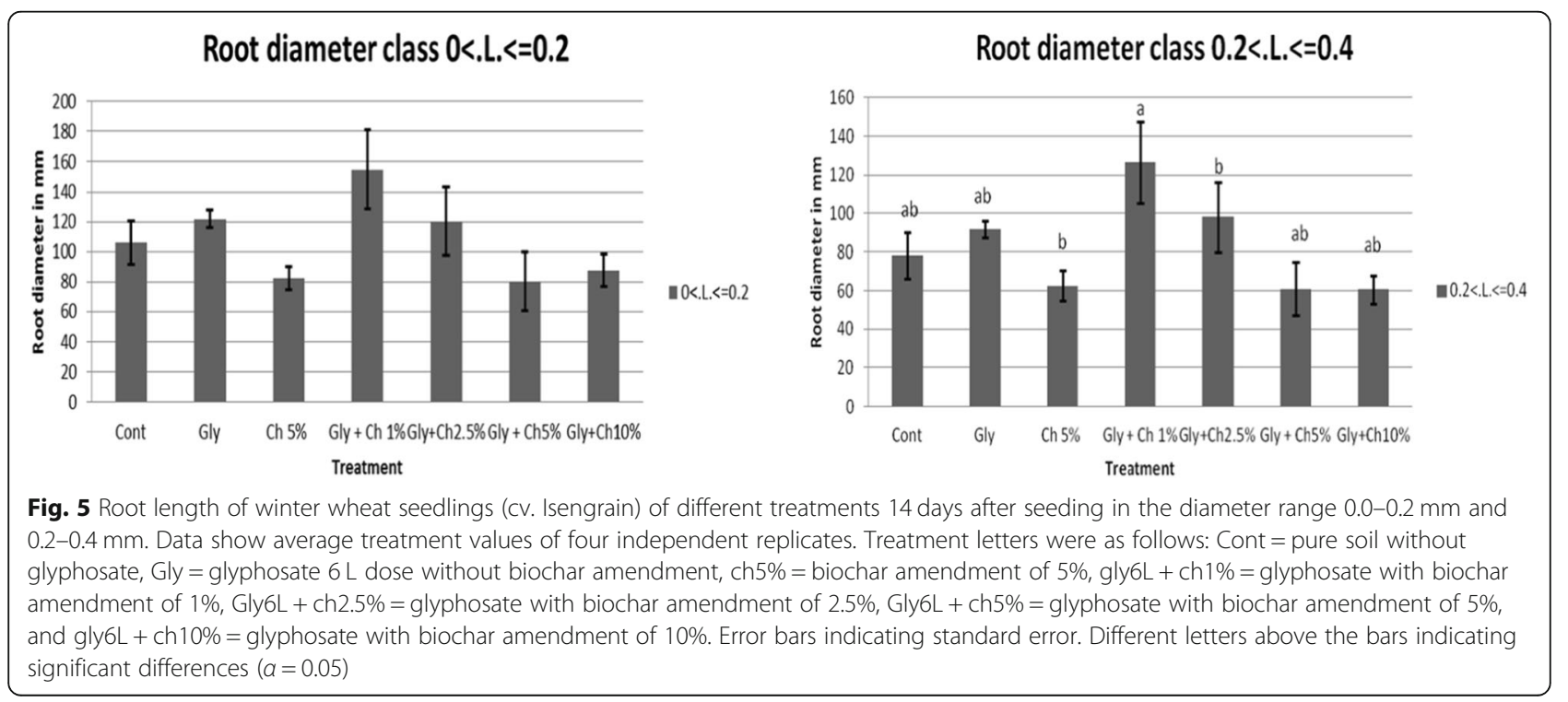




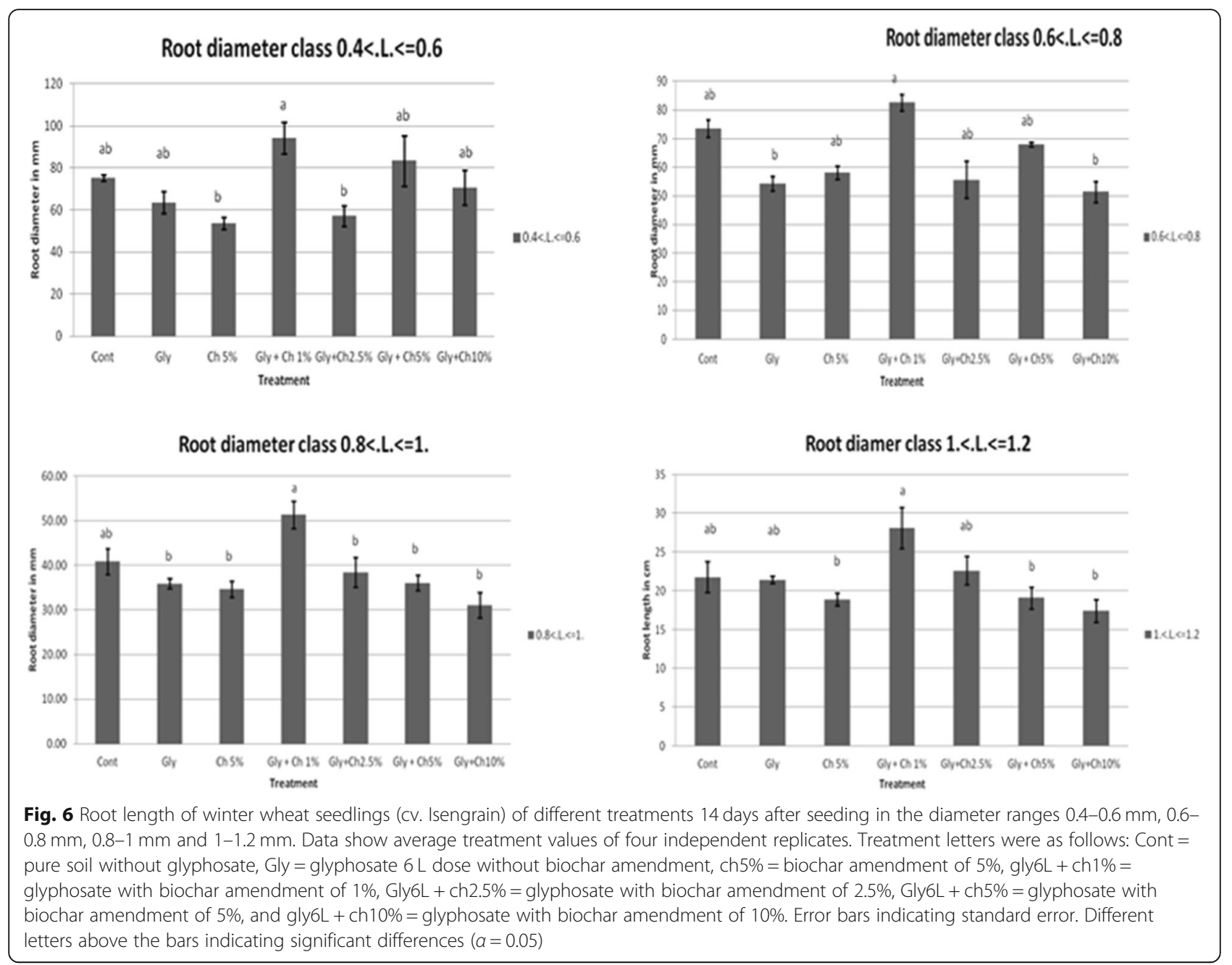

\section{Root length $(\mathrm{cm})$}

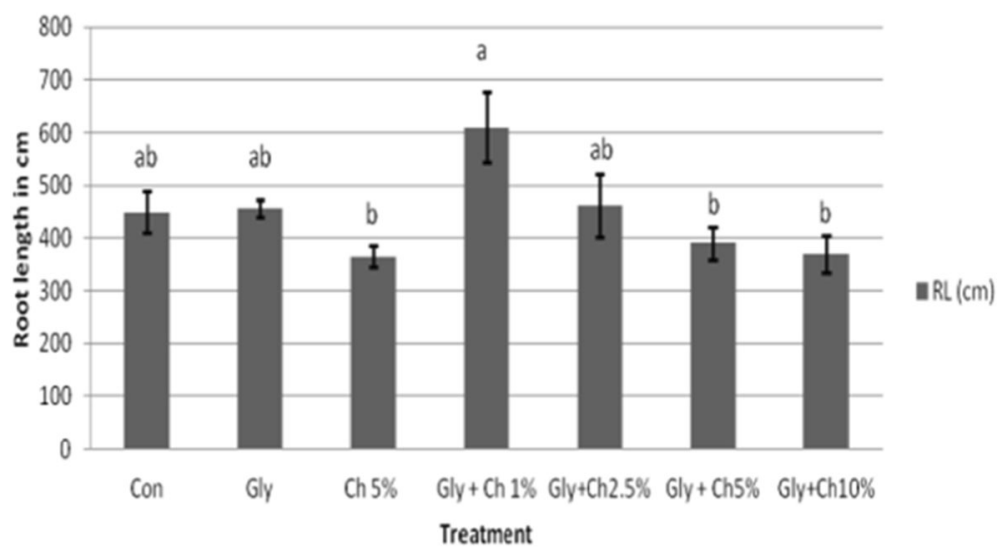

Fig. 7 Total root length of winter wheat seedlings (cv. Isengrain) of different treatments 14 days after seeding. Data show average treatment values of four independent replicates. Treatment letters were as follows: Cont = pure soil without glyphosate, Gly $=$ glyphosate $6 \mathrm{~L}$ dose without biochar amendment, ch5\% = biochar amendment of 5\%, gly $6 \mathrm{~L}+$ ch $1 \%=$ glyphosate with biochar amendment of 1\%, Gly $6 \mathrm{~L}+$ ch $2.5 \%=$ glyphosate with biochar amendment of $2.5 \%$, Gly $6 \mathrm{~L}+\mathrm{ch} 5 \%=$ glyphosate with biochar amendment of 5\%, and gly $6 \mathrm{~L}+\mathrm{ch} 10 \%=$ glyphosate with biochar amendment of 10\%. Error bars indicating standard error. Different letters above the bars indicating significant differences $(a=0.05)$ 


\section{Root average diameter $(\mathrm{mm})$}

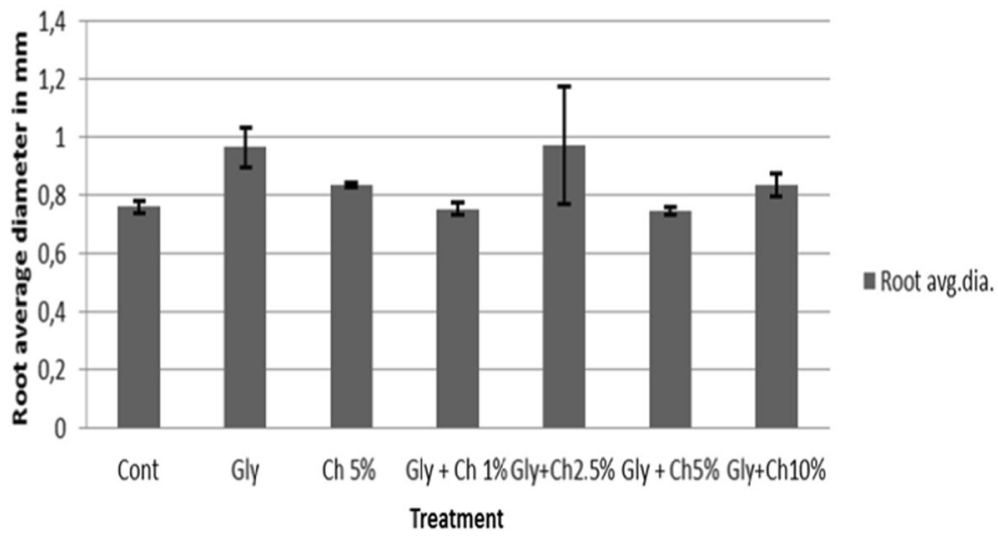

Fig. 8 Root average diameter of winter wheat seedlings (cv. Isengrain) of different treatments 14 days after seeding. Data show average treatment values of four independent replicates. Data show average treatment values of four independent replicates. Error bars indicating standard error

fine root growth, possibly by sorption of herbicide molecules or decreases the negative effect of glyposate to fine root development. Moreover, Gly + ch1\% performed higher in root length compared to Gly + ch2.5\% Gly + ch $5 \%$, Gly + ch 10 , and biochar $5 \%$ in the diameter range $0.0 \mathrm{~mm}$ to above $0.6 \mathrm{~mm}$. These results are indicating a positive trend of lower rate of biochar amendment in root length at glyphosate-treated soil. In addition, among all biochar treatment, Gly + ch1\% revealed better performance in total root length compared to Gly + ch $2.5 \%$, Gly $+\operatorname{ch} 5 \%$, Gly $+\operatorname{ch} 10 \%$, and ch $5 \%$, respectively. This result is demonstrating lower dose of biochar amendment which is better for fine root length development. It is clear that only seedling emergence was slightly affected by the glyphosate treatments, and this effect was mitigated by $5 \%$ biochar application. Thereafter, the seedling roots were obviously able to escape into deeper, non-contaminated soil layers. Due to the low mobility of glyphosate in soils, soil contaminations after spraying under field conditions are also expected to be mainly restricted to the top soil layers. However, herbicide residues released from decaying weed roots may contaminate also deeper soil layers. The same holds true for soil movements in minimal tillage or strip till systems and also during sowing in no-tillage practice.

\section{Conclusion}

Finally, it can be concluded that application of glyphosate has a mitigating impact on herbicide residue absorption. Applying biochar to farmers successfully serves as an enormous carbon sink and also has a beneficial impact on upcoming future climate.

\section{Acknowledgments}

The authors are thankful to the departmental lab for provision of laboratory facilities to carry out this research.

\section{Authors' contributions}

AS did the conceptualization, data curation, writing-original draft, and preparation. MASJ, MF, MAA, and SRS did the writing-review and editing. MAR is responsible for the supervision. AS, MF, and SRS carried out the data analysis and visualization. All authors revised, read, and approved the final manuscript.

\section{Funding}

There are currently no funding sources in the design of the study and collection, analysis, and interpretation of data and in writing the manuscript.

Availability of data and materials

The datasets generated and/or analyzed during the current study are included in this study.

Ethics approval and consent to participate Not applicable.

\section{Consent for publication}

Not applicable.

Competing interests

The authors declare that they have no competing interests.

\section{Author details}

'Institute of Environmental and Sustainable development in Agriculture, Chinese Academy of Agricultural Science, Beijing 10081, China. Institute of Crop Sciences, Chinese Academy of Agricultural Sciences, Beijing 10081, China. Institute of Agricultural Resources and Regional Planning, Graduate school of Chinese Academy of Agricultural Science, Beijing 10081, China.

${ }^{4}$ Department of Horticulture, Bangladesh Agricultural University, Mymensingh, Bangladesh. 
Received: 17 August 2019 Accepted: 28 October 2019

Published online: 28 November 2019

\section{References}

Adl S, Coleman D, Read F (2005) Slow recovery of soil biodiversity in sandy loam soils of Georgia after 25 years of no-tillage management. Agric Ecosyst Environ 114:323-333

Alvarez R, Steinbach H (2009) A review of the effects of tillage systems on some soil physical properties water content nitrate availability and crops yield in the Argentine Pampas. soil till Res. 114:1-15

Babujia L, Hungria M, Franchini J, Brookes P (2010) Microbial biomass and activity at various soil depths in a Brazilian oxisol after two decades of no-tillage and conventional tillage. soil biol Biochem. 42:2174-2181

Bhattacharyya R, Prakash V, Srivastva A, Kundu S, Gupta H (2009) Soil aggregation and organic matter in a sandy clay loam soil of the Indian Himalayas under different tillage and crop regimes. Agric, Ecosyst Environ. 132:126-134

Cavalieri K, Silva A, Tormena C, Leão T, Dexter A, Hakansson I (2009) Long-term effects of no-tillage on dynamic soil physical properties in a Rhodic Ferrasol in Paraná Brazil, soil till, res.103:158-164

Chen B, Yuan M (2011) Enhanced sorption of polycyclic aromatic hydrocarbons by soil amended with biochar. J Soils Sediments 11:62-71

Della-Cioppa G, Bauer S, Klein B (1986) Translocation of the precursor of 5 enolpyruvylshikimate-3-phosphate synthase into chloroplasts of higher plants in vitro. Proc, Natl, Acad, Sci United States Am 83(18):6873-6877

Derpsch R, Sidiras N, Roth C (1986) Results of studies made from 1977 to 1984 to control erosion by cover crops and no-tillage techniques in Paraná Brazil. soil till Res. 8:253-263

Dong-Mei Z, Yu-Jun W, Long C, Xiu-Zhen H, Xiao-San L (2004) Adsorption and cosorption of cadmium and glyphosate on two soils with different characteristics. hemosphere 57:1237-1244

Franz J, Mao M, Sikorski J (1997) Glyphosate: a unique global herbicide. American Chemical Society chapter 4

Giesy J, Dobson S, Solomon K (2000) Ecotoxicological risk assessment for roundup ${ }^{\circledR}$ herbicide, pp 35-120

Grossman J, O'Neill B, Tsai S, Liang B, Neves E, Lehmann J, Thies J (2010) Amazonian anthrosols support similar microbial communities that differ distinctly from those extant in adjacent unmodified soils of the same mineralogy. microb Ecol. 60:192-205

Huber DM, McCay-Buir TS (1993) A multiple component analysis of the take-all disease of cereals. Plant Dis 77:437-447

Jin H, Hongwen L, Rasaily RG, Qingjie W, Guohua C, Yanbo S, Xiaodong Q, Lijin L (2011) Soil properties and crop yields after 11 years of no tillage farming in wheat-maize cropping system in North China plain. Soil Till, Res 113:48-53

Khan KT, Chowdhury MTA, Imamul SM (2014) Application of biochar and fate of soil nutrients. Bangladesh J Sci Res 27(1):11-25

King C, Purcell L, Vories E, Glyphosate N (2001) Plant growth and nitrogenase activity of glyphosate-tolerant soybean.179-186

Kuzyakov Y, Subbotina I, Chen H, Bogomolova I, Xu X (2009) Black carbon decomposition and incorporation into microbial biomass estimated by $14 \mathrm{C}$ labeling. soil biol Biochem. 41:210-219

Laird D, Brown R, Amonette J, Lehmann J (2009) Review of the pyrolysis platform for coproducing bio-oil and biochar. Biofuels Bioprod Biorefining 3:547-562

Lehmann J (2006) Bio char sequestration in terrestrial ecosystems - a review. Mitig, adapt, Strateg, glob Chang. 11:403-427

Lehmann J (2007) A handbook of. Carbon. 447:143-144

Liang B, Lehmann J, Solomon D, Kinyangi J, Grossman J, O'Neill B, Skjemstad JO, Thies J, Luizão FJ, Petersen J, Neves EG (2006) Black carbon increases cation exchange capacity in soils. soil Sci, Soc Am. 70:1719-1730

Lima C, Reinert D, Reichert J, Suzuki L (2010) Produtividade de culturas e resistência à penetração de Argissolo Vermelho sob diferentes manejos (yield of crops and soil resistance to penetration of the Alfisol under different management). Pesq, Agropec Bras. 45:89-98

Minolta Co (2013) Manual for chlorophyll meter SPAD-502 plus. Minolta Camera Co., Osaka, Japan

Müller D (2011) Auspragung von Schadsymptomen bei Winterweizen im Vergleich von Anbauflachen mit langjahriger und kurzjahriger pflugloser Anbaupraxis im Gefäßversuch. Bachelorarbeit, Institut für Kulturpflanzenwissenschaften (340h), Universität Hohenheim

Neumann G, Afzal J, Römheld V (2012) Neue Erkenntnisse zur Nachbauproblematik von Winterweizen im Direktsaatanbau, Institut für Kulturpflanzenwissenschaften (340h) Universität Hohenheim. Präsentation in Powerpoint
O’Neill B, Grossman J, Tsai M, Gomes J, Lehmann J, Peterson J, Neves E, Thies J (2009) Bacterial community composition in Brazilian anthrosols and adjacent soils characterized using culturing and molecular identification. microb Ecol. 58:23-35

Piccolo A, Celano G, Pietramellara G (1992) Adsorption of the herbicide glyphosate on a metal-humic acid complex. Sci Total Environ 124:77-82

Putte V, Govers V, Diels J, Gillijns K, Demuzere M (2010) Assessing the effect of soil tillage on crop growth: a meta-regression analysis on European crop yields under conservation agriculture. Eur, J Agron. 33:241-251

Schmitz P, Nomman M, Garvert H, Hesse J (2012) Was wäre wenn Glyphosat in Deutschland nicht mehr eingesetzt werden dürfte? DLG Mitteilungen 2:20-21

Simpson D (2008) Biofilm processes in biologically active carbon water purification. Water Res 42:2839-2848

Solaiman M, Murphy D, Abbott L (2012) Biochars influence seed germination and early growth of seedlings, plant soil. 353:273-287; doi: 10,1007/ s11104-011-1031-4

Sun K, Gao B, Ro K, Novak J, Wang Z, Herbert S, Xing B (2012) Assessment of herbicide sorption by biochars and organic matter associated with soil and sediment. environ Pollut. 163:167-173

Wardle D, Nilsson ZM (2008) Fire derived charcoal causes loss of forest humus. Science. 320(80):629-621

Warnock D, Lehmann J, Kuyper T, Rillig M (2007) Mycorrhizal responses to biochar in soil concepts and mechanisms. Plant Soil 300:9-20

Woolf D, Amonette J, Street-Perrott A, Lehmann J, Joseph S (2010) Sustainable biochar to mitigate global climate change. Nat Commun 1-56

\section{Publisher's Note}

Springer Nature remains neutral with regard to jurisdictional claims in published maps and institutional affiliations.

\section{Submit your manuscript to a SpringerOpen ${ }^{\circ}$ journal and benefit from:}

- Convenient online submission

- Rigorous peer review

- Open access: articles freely available online

High visibility within the field

- Retaining the copyright to your article

Submit your next manuscript at $>$ springeropen.com 